\title{
Интерсубъективный принцип управления инновационным развитием регионов
}

\author{
Моисеева Татьяна Владимировна, Мятишкин Юрий Владимирович \\ Самарский федеральный исследовательский центр РАН, Институт проблем \\ управления сложными системами РАН, РФ, 443020, г. Самара, ул. Садовая, 61
}

\begin{abstract}
Аннотация. Устойчивое развитие регионов должно в конечном счете привести к обновлению и расширению средств потребления. От того насколько это качественно делается и зависит рост уровня жизни в обществе. В современном обществе сделан основной упор в появлении новшеств в процессе производства. В связи с этим инновационное развитие рассматривается как средство извлечения прибыли. При этом утрачивается связь с широкими интересами потребителей, в поле внимания остается только увеличение способности товаров реализовывать свое изначальное назначение. Работа над комплексной постановкой задач бизнесу со стороны потребителей должна стать первоисточником для определения конструкции товаров и направления технологического развития производства. В связи с этим предлагается новое понимание инновационной идеи как результата совместного разрешения проблемной ситуации акторами, осознающими себя внутри проблемной ситуации. В качестве средства реализации субъектноориентированного подхода к инновационному развитию предлагается формирование территориальных потребительских кооперативов нового типа.
\end{abstract}

Ключевые слова: инновационное развитие, самоуправление, предновация, инновация, интерсубъективное управление, потребительская кооперация.

\section{Введение}

Актуальной задачей современности является поиск путей сбалансированного улучшения экономического, социального и экологического аспектов развития регионов, составляющих основу их устойчивого развития. Решения, принимаемые в этой сфере, носят, преимущественно, бюрократический характер в том смысле, что они отражают образ развития регионов, сложившийся в сознании представителей административно-чиновничьей власти.

Ее действия по улучшению материального и социального положения жителей регионов преимущественно осуществляются в соответствии с собственным виденьем, распоряжениями вышестоящего начальства и имеющихся предложений на рынке. Учет мнения граждан осуществляется в большой степени формально. В итоге 
на бюджетные средства нередко создаются неэффективные или, вообще, мало кому нужные объекты, которые, наоборот, скорее снижают качество жизни граждан.

Способ определения того, что действительно полезно гражданам и обществу в целом представляет собой интерес не только с точки зрения повышения качества потребления граждан, но и появления новых объектов выгодных инвестиций для бизнеса и роста налогооблагаемой базы на этой почве в интересах государства.

В основе нового понимания устойчивого развития региона лежит предлагаемое в данной статье новое понимание инновации, как результата коллективного поиска выхода из проблемных ситуаций простых людей, населяющих регион.

Широко распространенное понимание инновации в большей степени соответствует его определению, введенному в научный оборот австрийским и американским экономистом Йозефом Алоизом Шумпетером. Инновацию он определил как явление, характеризующее возникновение чего-то нового, ранее неизвестного, повышающего эффективность действующей системы [1]. Областью инновационной деятельности изначально было определено предпринимательство, и такое понимание инноваций, сформировавшееся в начале XX века, по преимуществу связанное с экономической сферой, оказало существенное влияние на понятийный инструментарий инноватики, активно внедряемый сегодня.

Большинство авторов, исследующих проблемное поле инноватики, трактует «инновацию» как продукт, не существовавший ранее, либо процесс, направленный на производство данного продукта. Поэтому инноватика в большинстве случаев ассоциируется с научно-техническими изобретениями или продуктами, приносящими прибыль, которые можно использовать на рынке, либо технологическая новация в структуре производства, приносящая экономическую прибыль.

Такое понимание инноваций и их роли в экономике, с нашей точки зрения, исчерпало себя. Новаторская деятельность должна распространиться за пределы конструкторских бюро и научных институтов, приблизившись к реальным проблемам рядовых граждан. Для этого необходимо создание новых социальных инструментов, позволяющих осуществлять данное взаимодействие.

\section{1 Развитие товаров как средства разрешения проблемных ситуации потребителей}

Понимание инновации как средства разрешения проблемной ситуации акторов было представлено в теории интерсубъективного управления, которая начала развиваться десятилетие назад [6-9]. Новая теория предлагает методологическую основу управления разрешением проблемных ситуаций группой акторов.

Главная идея теории заключается в том, что оказавшись в проблемной ситуации, активные люди (акторы) начинают искать других участников ситуации, на добровольной основе образовывать с ними самоорганизованные сообщества, в ходе коммуникаций строить интерсубъективную онтологическую модель ситуации и совместно искать решение [10, 11], привлекая, в том числе, компетентных специалистов, представителей хозяйственных организаций, а также местной власти. Найденное решение и есть инновация - результат осмысления акторами проблемной ситуации, который формулирует представление о некотором нововведении, с помощью которого ее можно было бы урегулировать и которое создаст дополнительную ценность для акторов [12, 13].

Любая инновация направлена на то, чтобы разрешить те или иные проблемы (задачи) потребителя. Отличие инновационного продукта от уже существующего заключается в том, что его пользователь решает свои проблемы совершенно иным способом, чем 
другие люди, оказавшись в подобной ситуации. Ценность инновации определяется тем, насколько хорошо новый продукт разрешает проблемы своего пользователя. Эта ценность в итоге порождает готовность будущего потребителя вкладывать ресурсы в его создание или в покупку какого-либо готового средства.

Процесс появления новых продуктов характеризует инновационное развитие. Для его интенсификации необходимо управлять процессом разрешения проблемных ситуаций. Поэтому необходимо изучение и обобщение настоящих и будущих проблем граждан, общества в целом. Организацию их планомерного разрешения целесообразно проводить после осмысления природы происхождения проблем в сообществах участников разрешения проблемы. Только после этого точнее прояснятся истинные потребности граждан, которые и целесообразно удовлетворять. Сегодня мы наблюдаем отрыв истинных потребностей граждан от того, что предоставляется производством. Прослеживается сильная однобокость предлагаемых средств разрешения потребительских задач с упором на технические свойства. Контекст использования производимых товаров мало учитывается. Сами новые товары создают множество проблем (социальных, экологических, материальных и пр.), которые в процессе усовершенствования изначального назначения товара выпадают из поля рассмотрения товаропроизводителей.

Сегодня эта проблема стала острее. Новые средства стали мощнее, сильнее, производительнее, и их номенклатура существенно расширилась. Поэтому пользование современными товарами все больше и больше затрагивает интересы окружающих людей. Становится теснее, более шумно, появляется больше выбросов, загрязняющих атмосферу, мусора и пр. Нарушение интересов граждан осуществляется уже не ручным, а механизированным способом, и это заметно обостряет проблемы. Технические средства большей мощности являются источником техногенных аварий куда более разрушительного характера, чем поломки простых ручных приспособлений, которые доминировали в обиходе у наших предков.

Сегодня требования к новым индустриальным товарам формируются на основе маркетинговых исследований, на их основе конструкторы находят те или иные технические и технологические решения, базирующиеся на современных научных исследованиях. Далее документация передается на производство, как правило, представляющее собой весьма сложный технологический процесс. Очень многие современные товары усложнились до такой степени, что разобраться со всеми их свойствами среднему обывателю становится весьма затруднительно.

Развитие производства все больше усиливает разрыв между уровнями компетентности производителей и потребителей. Сегодня покупатель оказался в таком положении, когда он не способен адекватно оценить предоставляемые потребительские возможности предлагаемых товаров и все больше вынужден полагаться на бренд, чем на информацию о реальных физических свойствах покупаемого. Получив в свое распоряжение приобретенную продукцию, ее пользователь, будучи недостаточно образованным, не может использовать полученное в полной мере. Таким образом, он покупает избыточные для себя свойства, то есть ненужное.

Список проблем техногенного характера пополняется социальными и психологическими проблемами, возникающими из-за того, что у граждан ослабла заинтересованность друг в друге, а, следовательно, и необходимость договариваться и учитывать интересы окружающих людей.

Возникновение спроса на почве разрешения проблем, вызванных новым потреблением, нельзя назвать позитивным явлением, так как разумнее не допускать возникновения проблем, чем исправлять последствия. 


\section{2 Развитие местного самоуправления}

Для реализации управления проблемными ситуациями необходимы регулярные переговоры граждан для достижения согласия по предметам и методам потребления в территориальных сообществах. Предлагается организовать региональные потребительские кооперативы, и в рамках данных организаций проводить обсуждения потребительских тем для осуществления ими совместных покупок. В этих же сообществах можно реализовать систему повышения потребительской грамотности.

Коллективное обсуждение потребительских задач способствует повышению качества совершаемых покупок за счет осмысленной подготовки требований к поставляемым товарам. Поэтому в местных потребительских сообществах целесообразно выполнять предпроектную работу по формированию технических заданий производителям. Таким образом можно вывести инновационную деятельность, главным элементом которой становится совместное принятие решений, на новый уровень развития.

Необходимо формирование потребительской кооперации нового типа, которая помимо совместных покупок, включит в себя развитую систему принятия совместных решений членами сообщества по согласованию предметов и методов потребления. Эти устойчивые соседские сообщества (современный аналог общин) должны стать источником нового спроса. Совместного потребления станет больше.

Средства коллективного потребления должны представлять собой не отдельные товары, а товарно-потребительские системы, включающие в себя помимо материальных объектов, правила их поочередного или совместного использования, методы общественного взаимодействия, алгоритмы работы технических систем.

Данные комплексные товары должны рождаться в рамках разрешения совместных проблемных ситуаций (потребительских задач), проводимого методами интерсубъективного управления, внутри групп. Основным мотивом взаимодействия должен стать не заработок (это не коммерческая организация), не подчинение насилию (это институт гражданского общества), а разрешение тех или иных проблемных ситуаций. Такой подход позволит обеспечить наиболее точное выявление потребительских интересов для формирования задания исполнителям работ и производителям товаров.

Для формирования таких сообществ нужны вложения ресурсов в систему, обслуживающую взаимодействие участников. Вкладчиками должны быть все стороны общественного взаимодействия: в-первую очередь, граждане (это сулит им повышение качества жизни); во-вторых, бизнес (он получит новую форму сбыта) и, наконец, власть (для которой важно увеличение инвестиционной активности, так как это обеспечивает рост налогооблагаемой базы).

Такую деятельность по принятию согласованного решения по поводу разрешения проблемной ситуации следует отнести к прединновационной. Поэтому предлагаем ввести новый термин «предновация», обозначающий потребительское новшество описание воображаемого комплексного товара, которого еще нет, но видны некоторые его контуры, или есть часть опытного образца, достаточные для того, чтобы предприниматели осуществили вложение в создание стартапа. Предновационная деятельность заключается в создании образа желаемого товара (но не готового решения), способного поддерживать готовность своих будущих потребителей делать начальные вложения в то, чтобы он в конце концов был создан предпринимателями или силами самих потребителей и разрешил имеющуюся у них проблему.

Подобная деятельность существует и сегодня. Граждане сами создают множество средств, которые не имеют для их авторов перспектив коммерческого применения, 
для личного использования. Это всевозможные поделки, постройки и прочее. Особое место занимают программные средства, становящиеся продуктами с «открытым кодом». Данная деятельность возникает на почве отсутствия готовности или возможности купить товар, идентичный создаваемому, самостоятельно. Зачастую создаются новшества, они разрешают проблемные ситуации местного значения.

Пользователи обмениваются опытом и информацией, объединяясь в самоорганизованные сообщества, совершенствуют не только продвигаемый на рынок оригинальный продукт, но и технологии его создания, подчиняясь решению главной задачи - улучшить собственную пользовательскую практику.

Продвижению и популяризации концепции «открытых инноваций» сегодня способствуют теоретические разработки Eric von Hippel, H.W. Chesbrough $[2,3,4,5]$ и др. Суть концепции заключается в том, что компании, разрабатывающие новые продукты и технологии, должны использовать не только собственные внутрикорпоративные научные разработки, но и активно внедрять инновации, компетенции и креативные способности из внешней среды, обращаясь к пользовательским инновациям, как правило, не связанным с научными исследованиями и их приложениями [Chesbrough, 2003].

В качестве результата предновационной деятельности предлагается формировать потребительский запрос, близкий по смыслу техническому заданию на изготовление товара, но таковым в полной мере не являющийся. Это не четкое задание исполнителю работ (поставщику), так как, с одной стороны, потребитель не знает всех возможностей производства, а, с другой, производитель берет на себя риски, связанные с готовностью других людей покупать создаваемую новую продукцию, и должен учитывать интересы более широкого круга потребителей.

Предновация - это продукт трудовой деятельности людей и их материальных вложений, поэтому она сама по себе является товаром, право на который принадлежит участникам поиска метода разрешения проблемной ситуации. Предновацию можно сопоставить с первой маркетинговой стадией производства товара (товар по замыслу), однако она является более совершенным продуктом.

\section{Заключение}

1. Предлагаемый субъектно-ориентированный подход к инновационному развитию позволит не только удовлетворить потребности людей, но и вывести работу по устойчивому развитию регионов на новый научно-методический уровень. Это потребует изменений не только в отношениях общества с бизнесом, но и общества с властью.

2. Предлагаемое изменение формата экономики потребует развития навыков межличностного взаимодействия рядовых граждан, которое будет направлено на учет широкого спектра интересов участников группового и общественного взаимодействия. Это будет способствовать гуманизации общества.

3. Очевидно, что изложенный подход к организации экономики смещает серийное производство в сторону меньшей массовости, более высокого качества и появления существенных отличительных признаков новых предметов потребления (по сравнению с аналогами). Это дорогие товары, а значит, они должны более длительно и интенсивнее использоваться, чтобы хватало имеющейся покупательной способности на прежнюю номенклатуру товаров. Помимо ускорения технологического развития, это позволит революционно снизить антропогенную нагрузку на окружающую среду.

4. Интерсубъективное принятие решения по методу разрешения общей проблемы должно включать все стороны потребления новых товаров: от физических свойств и 
правил использования до способа утилизации. Это позволит наиболее широко разрешить текущую потребительскую задачу граждан и максимально избежать проблем в будущем.

5. Изменение способа потребления создаст естественную защиту внутренних рынков за счет уникальности местного хозяйства, требующего особых (иных) технологий для разрешения своих местных хозяйственных задач. Однако на этой почве можно прогнозировать проблему дефицита необходимых товаров, которую придется постоянно решать на каждом новом историческом этапе по-своему.

6. Вовлечение широкого числа участников в преодоление какой-либо общей проблемы обеспечивает организаторов ее разрешения большим объемом информации о сути самой проблемы и о возможных методах ее преодоления. Помощь в разрешении проблем граждан со стороны чиновников с привлечением бюджетных средств обеспечит их дополнительными возможностями влияния на людей и снизит тем самым необходимость применения насилия со стороны государственной власти. Таким образом характер государственного управления изменится в сторону большей демократизации.

\section{Литература}

1. J. Schumpeter, History of Economic Analysis (1963).

2. H. Chesbrough, Open Innovation: The New Imperative for Creating and Profiting from Technology (2003).

3. H. Chesbrough, Open Business Models. How to Thrive in the New Innovation Landscape (2006).

4. E. von Hippel, Jeroen de Jong, Open, Distributed and User-Centered: Towards a Paradigm Shift in Innovation Policy (2010).

5. G. Mulgan, S. Tuckers, R. Ali, B. Sanders, Social Innovation: What It Is, Why It Matters and How It Can be Accelerated (2007).

6. Vladimir A. Vittikh, Group Decision and Negotiation. 24(1), 67 (2015)

7. Vladimir A. Vittikh, Group Decision and Negotiation, 24(5), 825 (2015)

8. Vladimir A. Vittikh, Group Decision and Negotiation, 24(6), 949 (2015)

9. Vladimir A. Vittikh, Int. J. Management Concepts and Philosophy, 9(2), 63 (2016)

10. T.V. Moiseeva, N.Yu. Polyaeva, Proc. 8th Scientific Conference on Information Technologies for Intelligent Decision Making Support, https://doi.org/10.2991/aisr.k.201029.004 (2020).

11. T.V. Moiseeva, Proc. XXI Int. Conf. "Complex Systems: Control and Modeling Problems" (CSCMP 2019). IEEE Xplore, 765, https://doi.org/10.1109/CSCMP45713.2019.8976828 (2019).

12. T.V. Moiseeva, S.V. Smirnov, Studies in Systems, Decision and Control, 199, 15, https://doi.org/10.1007/978-3-030-12072-6_2 (2019)

13. T.V. Moiseeva, Proceeding of the International Science and Technology Conference "FarEastCon 2019", 267 (2019) 